\title{
Prevalence of gonorrhoea among women using various methods of contraception
}

\author{
G. S. BERGER†, L. KEITH‡, AND W. MOSS § \\ From the + Department of Obstetrics and Gynecology, University of North Carolina, Chapel Hill, North \\ Carolina; the $¥ D$ Department of Obstetrics and Gynecology, Chicago Medical School/University of Health Sciences, \\ and §formerly of the Department of Obstetrics and Gynecology, Louisiana State University, Shreveport, \\ Louisiana
}

Family Planning clinics have been instrumental in locating asymptomatic women patients infected with Neisseria gonorrhoeae (Noonan and Adams, 1974). Of almost 5,000,000 patients screened for gonorrhoea, 22 per cent. were seen in Family Planning clinics (USPHS, 1972), and infection rates in these patients ranged from $2 \cdot 1$ to $3 \cdot 4$ per cent.

Many studies concerning the relationship between the prevalence of venereal disease and oral contraception have originated in venereal disease clinics (Cohen, 1970), but these clinics have a selected population with a high rate of infection with gonorrhoea (USPHS, 1972). Attempts to delineate the relationship between the intrauterine contraceptive device (IUD) and gonorrhoea are often confusing (Noonan and Adams, 1974) because it is difficult to distinguish between pelvic inflammatory disease and a pure gonorrhoeal infection without careful culture techniques. Some clinicians assume that pelvic inflammatory disease can be equated with gonorrhoeal infection, past or present (Wright, 1968), even in the absence of confirmation by microbiological studies. This assumption is debatable.

The present report is part of a study designed to evaluate the efficacy of cultures from three sites for the detection of gonorrhoea in a Family Planning clinic (Keith, Moss, and Berger, 1975). A possible association was observed between the risk of gonococcal infection and the use or non-use of contraceptives both in a general population and among a group of women in the puerperium. We also report on the prevalence of gonorrhoea associated with specific methods of contraception.

\section{Material and methods}

The study population consisted of women attending the Caddo Family Planning Clinic in Shreveport, Louisiana,

Received for publication December 16, 1974

Address for reprints: Dr. Louis Keith, Cook County Hospital, 1825 West Harrison Street, Chicago, Illinois, 60612, U.S.A.

Supported in part by Ortho Diagnostics, Inc., Raritan, New Jersey, U.S.A. between March 1 and September 7, 1973. All the patients included in the study voluntarily agreed to participate in the gonorrhoea detection programme; 177 women with ambiguous culture results which made diagnostic classification impossible were omitted. A further fourteen women were excluded from analysis because their records of contraceptive usage were incomplete. This left a final patient population of 2,005 women.

All laboratory tests were performed in a single laboratory deliberately set up for this study to ensure maximum quality control of culture techniques.

Individual cultures were obtained from:

(1) The endocervical canal;

(2) The cryptal area of the anus;

(3) The posterior oropharynx and tonsillar fossae.

Sterile cotton swabs were used, and once a specimen for culture was obtained, the swab was rolled onto ThayerMartin Medium in a ' $Z$ ' pattern. The inoculated Petri dishes were placed in a candle-extinction jar to maintain a $\mathrm{CO}_{2}$ atmosphere, and then removed to the laboratory where they were streaked with a sterile wire loop. The culture dishes were subsequently replaced in candle jars and incubated for $48 \mathrm{hrs}$.

After incubation, Gram stains were performed when the gross appearance of the colonies suggested $N$. gonorrhoeae. If Gram-negative diplococci were observed, an oxidase test was performed using the Baltimore Biologic Laboratories (BBL) differentiation disc for Neisseria and Pseudomonas. Presumptive positive reactions to cervical cultures were determined by:

(1) Growth on Thayer-Martin medium;

(2) A Gram-stain revealing Gram-negative diplococci;

(3) Positive reaction to the oxidase test.

Dextrose fermentation studies were carried out on specimens from oropharyngeal and rectal sites. The cultures of specimens from 177 patients $(8 \cdot 1$ per cent.) were discarded because of Proteus overgrowth, making identification of Neisseria impossible.

\section{Results}

Table I demonstrates the distribution of the patient population by method of contraception in use, if any, at the time of the clinic visit, along with prevalence rates of gonorrhoea for the corresponding groups of patients. Of the total population, slightly over half 
TABLE I Distribution of 2,005 patients attending family planning clinic by method of contraception in use at time of visit and prevalence of gonorrhoea ${ }^{\star}$

\begin{tabular}{|c|c|c|c|c|}
\hline \multirow{2}{*}{ Method of contraception } & \multicolumn{2}{|c|}{ Total patients } & \multicolumn{2}{|c|}{$\begin{array}{l}\text { Patients with } \\
\text { N. gonorrhoea }\end{array}$} \\
\hline & No. & Per cent. & No. & $\begin{array}{l}\text { Rate } \\
\text { per } / 100\end{array}$ \\
\hline $\begin{array}{l}\text { Oral } \\
\text { IUD } \\
\text { Condom-Diaphragm-Foam } \\
\text { None } \\
\text { Sterilization }\end{array}$ & $\begin{array}{r}862 \\
181 \\
72 \\
830 \\
60\end{array}$ & $\begin{array}{r}43 \cdot 0 \\
9 \cdot 0 \\
3 \cdot 6 \\
41 \cdot 4 \\
3 \cdot 0\end{array}$ & $\begin{array}{r}99 \\
18 \\
3 \\
65 \\
2\end{array}$ & $\begin{array}{r}11 \cdot 5 \\
9 \cdot 9 \\
4 \cdot 2 \\
7 \cdot 8 \\
3 \cdot 3\end{array}$ \\
\hline Total & 2,005 & $100 \cdot 0$ & 187 & $9 \cdot 3$ \\
\hline
\end{tabular}

*Excludes fourteen patients for whom the method of contraception was not known at time of visit

( 55.6 per cent.) were using a method of contraception at the time of the clinic visit. Most of the remaining women ( 41.4 per cent.) were not using any method of pregnancy prevention; a small group ( 3 per cent.) had been sterilized.

The highest prevalence rate of gonococcal infection, based on positive cultures from one or more sites, was associated with oral contraception (11.5 per cent.). This was followed in descending order by use of intrauterine devices ( 9.9 per cent.), no contraception ( 7.8 per cent.), condom-diaphragm-foam ( 4.2 per cent.), and previous surgical sterilization (3.3 per cent.). The difference between the prevalence rates associated with oral contraception versus IUD or condom-diaphragm-foam versus surgical sterilization were not significant (Fisher's exact test: $P>0.05$ ). On the other hand, the use of medical methods of contraception (oral or IUD) was associated with a significantly higher risk of infection than that observed with barrier methods (condom-diaphragmfoam) or sterilization $(P<0.05)$. However, because the patients using each method were dissimilar with regard to age, race, and postpartum status, such a simple comparison of infection rates by method of contraception may be misleading.

TABLE II Differences in use of contraceptive method by age, race, and postpartum status

\begin{tabular}{|c|c|c|c|}
\hline Method & $\begin{array}{l}\text { Mean age } \\
\text { (S.D.) } \\
\text { (yrs) }\end{array}$ & $\begin{array}{l}\text { Percentage } \\
\text { White }\end{array}$ & $\begin{array}{l}\text { Percentage } \\
\text { Postpartum }\end{array}$ \\
\hline Oral & $\begin{array}{l}23 \cdot 1 \\
( \pm 5 \cdot 06)\end{array}$ & $6 \cdot 8$ & $0 \cdot 1$ \\
\hline IUD & $\begin{array}{l}25 \cdot 2 \\
( \pm 5 \cdot 76)\end{array}$ & $7 \cdot 2$ & 0.0 \\
\hline Condom-Diaphragm-Foam & $\begin{array}{l}\mathbf{2 4 \cdot 6} \\
( \pm 7 \cdot 20)\end{array}$ & $15 \cdot 3$ & $1 \cdot 4$ \\
\hline None & $\begin{array}{l}20 \cdot 6 \\
(+5.43)\end{array}$ & $11 \cdot 8$ & 52.5 \\
\hline Sterilization & $\begin{array}{l}30.9 \\
( \pm 6 \cdot 79)\end{array}$ & $3 \cdot 3$ & 0.0 \\
\hline Total & $\begin{array}{l}22 \cdot 5 \\
( \pm 5 \cdot 82)\end{array}$ & $9 \cdot 2$ & $21 \cdot 7$ \\
\hline
\end{tabular}

Table II shows that women not using contraceptives were younger (mean age $20.6 \mathrm{yrs}$ ), and that the sterilized women were older (mean age 30.9 ), than those using contraceptives whose mean ages ranged from 23.1 to $25 \cdot 2$ years. Twice as many of those using condom, diaphragm, or foam were white as those using oral methods or IUD. Since age and race are known risk factors for gonococcal infection in this study population (Keith and others, 1975), a more valid comparison of the prevalence rates of gonorrhoea associated with different contraceptive methods can be made by comparing patients of similar age and race.

In Table III, a comparison is made of infection rate by site of infection between women using oral methods, IUDs, and barrier methods, excluding the small proportion of white women in the study. The difference in infection rates between oral contraceptive and IUD users was not significant, but the raised cervical infection rates with oral methods or IUD as compared with barrier methods was statistically significant. There were no significant differences in rectal or oral infection rates associated with the method of contraception utilized by the patient.

TABLE III Prevalence of gonorrhoea by site of infection in women using contraceptives at time of clinic visit (nonwhites only)*

\begin{tabular}{|c|c|c|c|c|c|c|c|}
\hline \multirow[b]{2}{*}{ Method } & \multirow{2}{*}{$\begin{array}{l}\text { No. of } \\
\text { cases }\end{array}$} & \multicolumn{2}{|c|}{ Cervical } & \multicolumn{2}{|c|}{ Rectal } & \multicolumn{2}{|c|}{ Oral } \\
\hline & & No. & Rate & No. & Rate & No. & Rate \\
\hline $\begin{array}{l}\text { Oral } \\
\text { IUD }\end{array}$ & $\begin{array}{l}802 \\
168\end{array}$ & $\begin{array}{l}85 \\
16\end{array}$ & $\begin{array}{r}10.6 \\
9.5\end{array}$ & $\begin{array}{r}29 \\
4\end{array}$ & $\begin{array}{l}3.6 \\
2.4\end{array}$ & $\begin{array}{l}9 \\
2\end{array}$ & $\begin{array}{l}1.1 \\
1.2\end{array}$ \\
\hline $\begin{array}{l}\text { Condom-Diaphragm- } \\
\text { Foam (C-D-F) }\end{array}$ & 60 & 1 & $1 \cdot 7$ & 1 & 1.7 & 0 & 0.0 \\
\hline Total & 1,030 & 102 & 9.9 & 34 & $3 \cdot 3$ & 11 & $1 \cdot 1$ \\
\hline
\end{tabular}

*Difference in cervical infection rates for C-D-F users versus oral or IUD users significant at $P<0.05$ (Fisher's exact test)

Infection rates, by site of infection, are shown for women not using contraceptives by postpartum status at the time of the clinic visit in Table IV. The few white women have been excluded from this Table. Significant differences were not observed in the rates of infection by site of infection between recently

TABLE IV Prevalence rate of gonorrhoea by site of infection for women not using contraceptives at time of clinic visit (nonwhites only)

\begin{tabular}{|c|c|c|c|c|c|c|c|}
\hline \multirow{3}{*}{$\begin{array}{l}\text { Postpartum } \\
\text { status }\end{array}$} & \multirow{3}{*}{$\begin{array}{l}\text { No. of } \\
\text { cases }\end{array}$} & \multicolumn{6}{|c|}{ Site } \\
\hline & & \multicolumn{2}{|c|}{ Cervical } & \multicolumn{2}{|c|}{ Rectal } & \multicolumn{2}{|c|}{ Oral } \\
\hline & & No. & $\begin{array}{l}\text { Ratel } \\
100\end{array}$ & No. & $\begin{array}{l}\text { Rate/ } \\
100\end{array}$ & No. & $\begin{array}{l}\text { Rate/ } \\
100\end{array}$ \\
\hline $\begin{array}{l}\text { Yes } \\
\text { No }\end{array}$ & $\begin{array}{l}400 \\
332\end{array}$ & $\begin{array}{l}24 \\
28\end{array}$ & $\begin{array}{l}6 \cdot 0 \\
8 \cdot 4\end{array}$ & $\begin{array}{l}6 \\
6\end{array}$ & $\begin{array}{l}1.5 \\
1.8\end{array}$ & $\begin{array}{l}3 \\
3\end{array}$ & $\begin{array}{l}0.8 \\
0.9\end{array}$ \\
\hline Total & 732 & 52 & $7 \cdot 1$ & 12 & 1.6 & 6 & 0.8 \\
\hline
\end{tabular}


delivered patients visiting the contraception clinic for the postpartum examination and those who had not recently been pregnant. By 6 weeks after delivery, postpartum patients were just as likely to have gonococcal infection of the cervix, rectum, or mouth as nonpuerperal women who were not using any form of contraception at the time of their visit to the clinic.

\section{Discussion}

An increased prevalence of cervical gonorrhoea was associated with the use of medical methods of contraception as compared with barrier methods and surgical sterilization. Whether this represents a causal association cannot be determined on the basis of these data. Patients at increased risk of gonorrhoea, perhaps because of specific sexual habits, may be more likely to choose medical rather than other methods. Women who had undergone surgical sterilization were older than those who were using medical contraceptives. Such women may well have different patterns of sexual activity than the younger women selecting medical methods, but this information was not sought in this study.

The low infection rate among patients using barrier methods cannot be explained only by differences in age or racial characteristics. The fact that the rate of cervical infection was lower for patients using barrier methods than for patients of similar age and race using medical methods supports the hypothesis that barrier methods may be effective in preventing transmission of $N$. gonorrhoeae. The fact that women using barrier method had oral or rectal infection rates similar to those of women using oral contraceptives or IUD is consistent with the hypothesis of a protective effect of condom, diaphragm, or foam, since these methods may have been omitted during the practice or oral or rectal intercourse. The possible protective effect of the use of foam is supported by studies in vitro, which have shown that some brands of vaginal spermicides are gonococcidal presumably because of lowering of the vaginal $\mathrm{pH}$. In contrast, the use of oral contraceptives has been said to favour the growth of the gonococcus by contributing to an alkaline $\mathrm{pH}$ in the vagina (Johnson, 1974). However, in the present study, the prevalence of gonorrhoea among patients using oral methods or IUD was not significantly different from that among women using no contraceptives. Thus, we cannot conclude that the use of oral contraception in itself increases the risk of gonorrhoea.

Although the primary activity of a Family Planning Clinic is to help the patient prevent unwanted pregnancy, the detection and in some areas the treatment of venereal disease in such patients is important. To the task of detection and treatment of venereal disease should be added the goal of preventing the spread of venereal disease. Based on the data in this study, it seems reasonable to suggest that greater emphasis be given in contraceptive educational programmes to some of the less effective conventional methods of contraception.

Although the traditional approach to the return of sexual activity after obstetric delivery is to suggest that it should not begin for 6 weeks, the finding that gonorrhoea rate among the postpartum patients in this study was similar to that of nonpuerperal women suggests a rapid return to customary sexual activity, inadequate antenatal screening and treatment, or both. Current obstetrical practice includes gonorrhoea screening at the intitial antenatal visit. The failure to repeat culture before delivery or until the postpartum visit assumes that sexual activity has been discontinued for 6 to 9 months. Published evidence is lacking to support this assumption. From the point of view of preventing infection of the newborn, it makes more sense to screen the patient for gonorrhoea shortly before the expected date of confinement.

Patients should be encouraged to use barrier methods of contraception in the immediate puerperium until medical methods can be instituted.

\section{Summary}

Among 2,005 women attending a contraceptive clinic $9 \cdot 3$ per cent. were found to have gonorrhoea. When these women were classified according to the method of contraception used at the time of their initial visit to the clinic, the following prevalence of gonorrhoea was observed: oral contraceptives 11.5 per cent., intrauterine contraceptive devices 9.9 per cent., barrier methods (condom-diaphragm-foam) 4.2 per cent. These differences are statistically significant. The authors suggest that the additional protective advantage of barrier methods should be considered when the physician and patient are selecting appropriate methods of contraception.

\section{References}

Cohen, L. (1970) Brit. F. vener. Dis., 46, 108

Johnson, J. W. C. (1974) 'Gonorrhea in the Female', in 'Davis' Gynecology and Obstetrics', ed. J. J. Rovinsky, vol. 2, chap. 59. Harper and Row, New York

KeITH, L., Moss, W., and Berger, G. S. (1975) Amer. F. Obstet. Gynec., 121, 399

Noonan, A. S. and ADAMS, J. B. (1974) Amer.f. publ. Hlth, 64, 700

United States Public Health Service (1972) Morb. Mort. Wkly Rep., 21, 82

WRIGHT, N. H. (1968) Amer. F. Obstet. Gynec., 101, 979 